\title{
Inhaled Epoprostenol in ARDS
}

ARDS presents as a devastating entity characterized by severe hypoxemia, systemic inflammatory response, and high hospital mortality $(>30 \%) .{ }^{1}$ Despite years of research, the utilization of mechanical ventilation with low tidal volumes $(6 \mathrm{~mL} / \mathrm{kg}$ of ideal body weight) remains the only therapy that shows reduction in mortality in all severity groups. ${ }^{2}$ Systemic inflammation with subsequent multiorgan dysfunction represents the most commonly reported cause of death. Nevertheless, severe hypoxemia also contributes to poor outcomes in the short and long term. Consequently, a variety of treatments have been investigated to optimize oxygenation. Some of the aforementioned options, also known as rescue therapies, include (1) mechanical ventilation strategies, such as airway pressure release ventilation, ${ }^{3}$ high frequency oscillatory ventilation, ${ }^{4}$ inverse-ratio ventilation, recruitment maneuvers, ${ }^{5}$ and high PEEP levels; ${ }^{6}$ (2) prone positioning; ${ }^{7}$ (3) extracorporeal membrane oxygenation; ${ }^{8}$ and (4) pharmacologic treatments, including intravenous neuromuscular blockers, ${ }^{9}$ corticosteroids, ${ }^{10,11}$ and inhaled vasodilators.

Treatment with inhaled nitric oxide as a rescue therapy for ARDS has shown significant improvement in oxygenation for a short period of $48 \mathrm{~h}$. However, no benefit in terms of survival has been demonstrated. ${ }^{12}$ As the clinical effect of inhaled nitric oxide is counterbalanced by its very high cost, other inhaled pharmacologic alternatives were explored. Specifically, inhaled prostaglandins have been increasingly used. A recently published study that compared inhaled epoprostenol versus inhaled nitric oxide in patients with refractory hypoxemia revealed similar efficacy and safety outcomes. ${ }^{13}$ However, inhaled nitric oxide was 4.5-17 times more costly than inhaled epoprostenol, depending on contract price. ${ }^{13}$ Randomized clinical studies assessing the effectiveness of inhaled prostaglandins in ARDS have rarely been performed. A recent Cochrane review was able to identify only one clinical trial, which included 14 critically ill children with ARDS. ${ }^{14}$ This study

The author has disclosed no conflicts of interest.

Correspondence: Ariel M Modrykamien MD, Intensive Care Unit and Respiratory Care Services, Creighton University School of Medicine, 601 N 30th Street, Suite 3820, Omaha, NE 68130. E-mail: arielmodrykamien@creighton.edu.

DOI: $10.4187 /$ respcare. 03424 evaluated the effect of aerosolized prostacyclin versus placebo, showing no differences in its primary outcome (mortality). ${ }^{14,15}$ Consequently, our current knowledge regarding the efficacy of inhaled prostaglandins in severe hypoxemia comes primarily from observational and case studies. In fact, a very recent retrospective chart review, which included 16 patients treated with inhaled epoprostenol, showed that this therapy was able to improve oxygenation (defined as an improvement in $\mathrm{P}_{\mathrm{aO}_{2}} / \mathrm{F}_{\mathrm{IO}_{2}}$ of $>10 \%$ from the baseline) in $62.5 \%$ of the treated patients. ${ }^{16}$

In this issue of Respiratory CARE, Pacheo et $\mathrm{al}^{17}$ make a contribution to our understanding of the effectiveness of inhaled epoprostenol in patients with ARDS. Specifically, the authors assess whether clinical variables are able to predict hospital and 90-d mortality among a select group of subjects with ARDS treated with inhaled epoprostenol. On the basis of a retrospective review of all patients admitted with ARDS for a period of $8.5 \mathrm{y}$, they were able to include 216 ARDS subjects who were treated with inhaled

See the Original Study on Page 1178

epoprostenol. Important information (such as severity of illness; use of corticosteroids, neuromuscular blockers, and vasopressors; and fluid balance accumulation) was recorded as well. Interestingly, after adjusting for several cofactors, only 5 parameters were significantly associated with hospital mortality. The presence of sepsis (pulmonary or nonpulmonary source) and an international normalized ratio of $\geq 1.5$ were directly related to hospital mortality. Higher body mass index, trauma as the cause of ARDS, and improvement of $\mathrm{P}_{\mathrm{aO}_{2}} / \mathrm{F}_{\mathrm{IO}_{2}}$ after $24 \mathrm{~h}$ of epoprostenol therapy were all associated with lower hospital mortality rate. When mortality was assessed at $90 \mathrm{~d}$, the same variables maintained their relationship. Furthermore, a cumulative fluid balance of $>4 \mathrm{~L}$ during epoprostenol treatment was also directly associated with mortality. These results confirm prior knowledge regarding adverse outcomes in sepsis, ${ }^{1}$ coagulopathy, ${ }^{18}$ and liberal fluid management, ${ }^{19}$ but applied to this specific population.

The authors of this study should be commended for a variety of aspects. First, the study answers a question not previously addressed in the English literature. This is the first study that investigated predictors of mortality in subjects with ARDS treated with inhaled prostaglandins. Sec- 
ond, despite being a retrospective study including $8.5 \mathrm{y}$ of data, the authors carefully reviewed all relevant information of eligible subjects to confirm the presence of ARDS according to the most updated classification (Berlin definition). ${ }^{20}$ Third, other therapies currently used in the treatment of ARDS were accounted for in the analysis (ie, neuromuscular blockers, steroids), strengthening the generalizability of these results.

The study also has some weaknesses. First, its retrospective nature exposes it to selection and/or information biases. The fact that the mortality rate was 63\% (136/216) in a group of ARDS subjects with expected mortality rates in a range of $24-33 \%$, based on the their Sequential Organ Failure Assessment and Acute Physiology and Chronic Health Evaluation II scores, reveals that other unknown factors may have contributed to these poor outcomes. Second, information regarding use of alternative modes of mechanical ventilation or prone positioning was not provided. Hence, it is possible that mortality rates may have been affected by these variables rather than, or in addition to, the previously described predictors. Finally, as the study included subjects over a long period of time (2004-2012), it is likely that different standards of patient care have been used over time in ARDS subjects (eg, glucose control). Whether predictors of mortality remain the same when calculated on populations treated by current standards is unknown.

\section{Ariel M Modrykamien MD \\ Intensive Care Unit and Respiratory Care Services Creighton University School of Medicine Omaha, Nebraska}

\section{REFERENCES}

1. Rubenfeld GD, Caldwell E, Peabody E, Weaver J, Martin DP, Neff $\mathrm{M}$, et al. Incidence and outcomes of acute lung injury. N Engl J Med 2005;353(16):1685-1693.

2. The Acute Respiratory Distress Syndrome Network. Ventilation with lower tidal volumes as compared with traditional tidal volumes for acute lung injury and the acute respiratory distress syndrome. $\mathrm{N}$ Engl J Med 2000;342(18):1301-1308.

3. Varpula T, Valta P, Niemi R, Takkunen O, Hynynen M, Pettilä VV. Airway pressure release ventilation as a primary ventilatory mode in acute respiratory distress syndrome. Acta Anaesthesiol Scand 2004; 48(6):722-731.

4. Ferguson ND, Cook DJ, Guyatt GH, Mehta S, Hand L, Austin P, et al. High-frequency oscillation in early acute respiratory distress syndrome. N Engl J Med 2013;368(9):795-805.
5. Gattinoni L, Caironi P, Cressoni M, Chiumello D, Ranieri VM, Quintel M, et al. Lung recruitment in patients with the acute respiratory distress syndrome. N Engl J Med 2006;354(17):1775-1786.

6. Mercat A, Richard JC, Vielle B, Jaber S, Osman D, Diehl JL, et al. Positive end-expiratory pressure setting in adults with acute lung injury and acute respiratory distress syndrome: a randomized controlled trial. JAMA 2008;299(6):646-655.

7. Guérin C, Reignier J, Richard JC. Prone positioning in the acute respiratory distress syndrome. N Engl J Med 2013;369(10):980-981.

8. Peek GJ, Mugford M, Tiruvoipati R, Wilson A, Allen E, Thalanany $\mathrm{MM}$, et al. Efficacy and economic assessment of conventional ventilatory support versus extracorporeal membrane oxygenation for severe adult respiratory failure (CESAR): a multicentre randomised controlled trial. Lancet 2009;374(9698):1351-1363.

9. Papazian L, Forel JM, Gacouin A, Penot-Ragon C, Perrin G, Loundou A, et al. Neuromuscular blockers in early acute respiratory distress syndrome. N Engl J Med 2010;363(12):1107-1116.

10. Meduri GU, Headley AS, Golden E, Carson SJ, Umberger RA, Kelso T, Tolley EA. Effect of prolonged methylprednisolone therapy in unresolving acute respiratory distress syndrome: a randomized controlled trial. JAMA 1998;280(2):159-165.

11. Steinberg KP, Hudson LD, Goodman RB, Hough CL, Lanken PN, Hyzy R, et al. Efficacy and safety of corticosteroids for persistent acute respiratory distress syndrome. N Engl J Med 2006;354(16): 1671-1684.

12. Taylor RW, Zimmerman JL, Dellinger RP, Straube RC, Criner GJ, Davis K, Jr., et al. Low-dose inhaled nitric oxide in patients with acute lung injury: a randomized controlled trial. JAMA 2004;291(13): 1603-1609.

13. Torbic H, Szumita PM, Anger KE, Nuccio P, LaGambina S, Weinhouse $\mathrm{G}$. Inhaled epoprostenol vs inhaled nitric oxide for refractory hypoxemia in critically ill patients. J Crit Care 2013;28(5):844-848.

14. Afshari A, Brok J, Moller AM, Wetterslev J. Aerosolized prostacyclin for acute lung injury (ALI) and acute respiratory distress syndrome (ARDS). Cochrane Database Syst Rev 2010;(8):CD007733.

15. Dahlem P, van Aalderen WM, de Neef M, Dijkgraaf MG, Bos AP. Randomized controlled trial of aerosolized prostacyclin therapy in children with acute lung injury. Crit Care Med 2004;32(4):10551060.

16. Dunkley KA, Louzon PR, Lee J, Vu S. Efficacy, safety, and medication errors associated with the use of inhaled epoprostenol for adults with acute respiratory distress syndrome: a pilot study. Ann Pharmacother 2013;47(6):790-796.

17. Pacheo J, Arnold H, Skrupky L, Watts P, Micek ST, Kollef, MH. Predictors of outcome in 216 subjects with ARDS treated with inhaled epoprostenol. Respir Care 2014;59(8):1178-1185

18. McClintock D, Zhuo H, Wickersham N, Matthay MA, Ware LB. Biomarkers of inflammation, coagulation and fibrinolysis predict mortality in acute lung injury. Crit Care 2008;12(2):R41.

19. National Heart, Lung, and Blood Institute Acute Respiratory Distress Syndrome (ARDS) Clinical Trials Network, Wiedemann HP, Wheeler AP, Bernard GR, Thompson BT, Hayden D, et al. Comparison of two fluid-management strategies in acute lung injury. N Engl J Med 2006;354(24):2564-2575.

20. ARDS Definition Task Force, Ranieri VM, Rubenfeld GD, Thompson BT, Ferguson ND, Caldwell E, et al. Acute respiratory distress syndrome: the Berlin Definition. JAMA 2012;307(23):2526-2533. 